\title{
Of Silos and Systems: The Issue of Regionalizing Health Care
}

\author{
Scot H Simpson
}

$\mathrm{R}$ egionalization refers to the creation of an intermediary administrative and governance structure (often referred to as a regional health authority or board) that assumes responsibility for organizing and delivering health care services to a defined population. ${ }^{1}$ The formation of a regional health board shifts the responsibility for decisions about funding and allocating health care resources away from both individual organizations (for example, a community hospital board) and the provincial ministry of health. The main goals of regionalization are to help contain rising health care costs (through economies of scale), to improve responsiveness to and accountability for population health needs, and to increase public participation in health care decision-making. ${ }^{1}$ In essence, the responsibility for providing health care services moves away from the "silos" of fragmented, individual organizations (as just one example, before regionalization in Saskatchewan, the province had more than 400 individual health care organizations, such as acute care hospitals and community care groups ${ }^{2}$ ) to a "system" of health care that is delivered in an integrated fashion by a single regional organization.

Regionalization of health care delivery began in the late 1980s and early 1990s in all provinces except Ontario. ${ }^{3}$ These initiatives were undertaken in response to observations from a number of federal and provincial commissions, task forces, and public forums aimed at finding ways to improve the health care system. ${ }^{1}$ Each province has developed regional health boards that vary in number, scope of responsibilities, and membership. While some provinces have separate boards to oversee institutional and community services, most have regional health boards with a wide range of responsibilities, including medical clinics, health promotion and prevention, youth and family services, public health, cancer care, mental health, hospitals, and residential care programs. ${ }^{3}$ In most provinces, the members of regional health boards are appointed by the provincial minister of health.

Although there are a number of recognized challenges associated with operating an effective regional health board, I will focus on just 4 of these. One fundamental challenge is the requirement to characterize the relative importance of a wide variety of health care needs within the region. Advocates believed that regionalization would create equity of allocation of health care services; however, with the closure of many small-town hospitals and an apparent shift in power to urban centres,

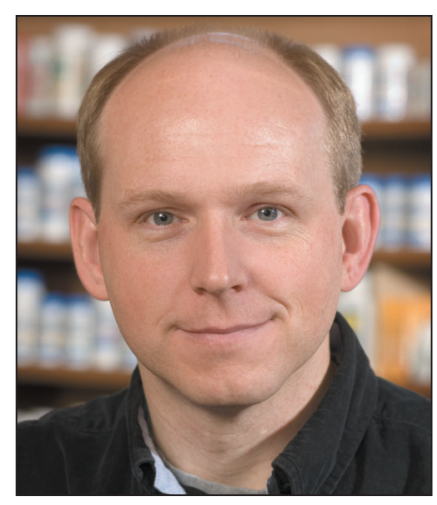
some would argue against this belief. ${ }^{4}$ To help make appropriate and equitable decisions, regional health boards would ideally use a valid and dynamic funding formula. ${ }^{5}$ However, such formulas require a complex amount of individual-level data, which reflects the second challenge: although individual-level data enable us to identify and account for important factors influencing health care needs, it is often difficult to access highquality, reliable epidemiological data. ${ }^{6}$ Ironically, the human resources and infrastructure needed to effectively gather and interpret this information may in fact exacerbate the problem of higher health care expenditures. ${ }^{1}$

A third challenge to the operation of regional health boards is the fact that many boards have limited authority to control major expenditures, such as physician fees and drug costs, as well as limited authority to create policy. ${ }^{4}$ Without devolution of power from provincial ministries of health, regional boards become another layer of administration in the health care system. Finally, public representation on regional health boards may be one of the biggest challenges of all. Although having such representation reflects a noble intent, selection of public members can be difficult. For example, if only one member of the public is involved on a particular board, it is critical to demonstrate that the individual selected speaks for the needs of all residents within the region. Inclusion of a public member with a vested interest in a limited number of issues can be harmful not only to the internal decision-making process of the 
board, but also to the external perception of how that board makes decisions. ${ }^{7}$

Over the 2 decades since their introduction, we have seen many adjustments to regional health boards. Certain of these changes have been made in response to public or political pressures or in attempts to address some of the challenges listed above. In some provinces, the number of boards has oscillated, along with their boundaries, scope of responsibilities, and composition of members. Clearly, there is no easy solution to the proper organization and delivery of health care services. One thing is certain, however: regionalization affects how we deliver care to our patients.

In this issue of the CJHP, the authors of the Point Counterpoint debate examine the pros and cons of different approaches to regionalization and how they affect the operation of pharmacy services within hospitals and related health care settings. ${ }^{8,9}$ Does a single regionalized pharmacy department help or harm the advancement of pharmacy practice? Taking a broader perspective, has regionalization of the health care system fulfilled the promises of cost containment, better responsiveness to and accountability for population needs, and more public involvement in your province? I will leave those judgements to you, our readers.

\section{References}

1. Church J, Barker P. Regionalization of health services in Canada: a critical perspective. Int J Health Serv 1998;28(3):467-486.

2. Marchildon GP. Regionalization and health services restructuring in Saskatchewan [conference paper]. In: Health services restructuring: new evidence and new directions; 17 Nov 2005; Kingston (ON). Montréal (QC): Institute for Research on Public Policy; 2005. Available from: www.irpp.org/events/archive/nov05JDI/marchildon.pdf
3. Health care in Canada. Ottawa (ON): Canadian Institute for Health Information; 2005.

4. Collier R. Is regionalization working? CMAJ 2010;182(4):331-332.

5. Smith PC, Rice N, Carr-Hill R. Capitation funding in the public sector. JR Stat Soc Ser A Stat Soc 2001;164(2):217-257.

6. Hurley J. Regionalization and the allocation of healthcare resources to meet population health needs. Healthc Pap 2004;5(1):34-39.

7. Abelson J, Forest PG, Eyles J, Smith P, Martin E, Gauvin FP. Obtaining public input for health-systems decision-making: past experiences and future prospects. Can Public Adm 2002;45(1):70-97.

8. Slobodan J, van Haaften D, Chambers CR. Is a single provincial pharmacy program beneficial for the advancement of pharmacy practice? The "pro" side. Can J Hosp Pharm 2011;64(4):285-286.

9. Wilson B. Is a single provincial pharmacy program beneficial for the advancement of pharmacy practice? The "con" side. Can J Hosp Pharm 2011;64(4):286-287.

Scot H Simpson, BSP, PharmD, MSc, is an Associate Professor with the Faculty of Pharmacy and Pharmaceutical Sciences, University of Alberta, Edmonton, Alberta. He is also an Associate Editor for the CJHP.

\section{Address correspondence to:}

Dr Scot H Simpson

Faculty of Pharmacy and Pharmaceutical Sciences

2125A Dentistry/Pharmacy Centre

University of Alberta

Edmonton AB T6G 2N8

e-mail: ssimpson@pharmacy.ualberta.ca

\section{ON THE FRONT COVER}

\section{Robson Square, Vancouver BC.}

Against a stunning indigo backdrop, the glass towers of Yaletown start to glow, one window at a time. Yaletown is an urban jewel that pulsates with a certain "je ne sais quoi" - truly Vancouverism at its best. A few blocks away, Vancouver will host the

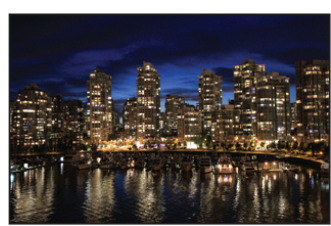

2011 Summer Educational Sessions from August 6 through 9. Welcome, and do stay awhile.
This photograph was taken from the Cambie Street Bridge in Vancouver, British Columbia, on a beautiful summer night in 2009. The photographer was Elaine Chong, a CSHP member, who continues to have an affinity for Canon digital SLRs and L-lenses.

The CJHP would be pleased to consider photographs featuring Canadian scenery taken by CSHP members for use on the front cover of the journal. If you would like to submit a photograph, please send an electronic copy (minimum resolution $300 \mathrm{dpi}$ ) to Colleen Drake at cdrake@cshp.ca. 